Tourism in Analysis

DOI: http://dx.doi.org/10.11606/issn.1984-4867.v27i3p644-667

\title{
Turismo de Base Comunitária: outras economias na mira da emancipação social ${ }^{l}$
}

\section{Community-Based Tourism: other economies targeting social emancipation}

Turismo de base comunitaria: otras economías en la mira de la emancipación social

Carolina Valéria de Moura Leão

\section{Resumo}

O sentido de comunidade tem sido a ideia-chave do Turismo de Base Comunitária (TBC), associando formas comuns de organização e gestão, em que esta é a principal beneficiária. Este artigo procura conhecer que mecanismos colaborativos e de gestão as comunidades recetoras têm desenvolvido, que sinalizem outras lógicas assentes na autogestão e na solidariedade, contrariamente à tendência da concentração empresarial e do lucro. Por sua vez, se estes se refletem em uma proposta de transformação social, com o aparecimento de novos sujeitos protagonistas no processo. Os elementos empíricos são obtidos a partir do recorte das informações incluídas no relatório de avaliação final externa de um projeto de TBC, em Timor Leste, tendo como foco três comunidades/cooperativas. O estudo revela a existência de novos sujeitos que se organizam na partilha de poderes e saberes, a partir de códigos de conduta e um conjunto de procedimentos de gestão colaborativa, apontando para um horizonte de emancipação social.

Palavras-chave: Turismo de Base Comunitária; Outras Economias; Emancipação Social.

\begin{abstract}
Community sense has been the main idea of Community-based Tourism (TBC), associating common ways of organization and management to benefit it. This article tries to find out what collaborative and management mechanisms the receiving communities have been developed, showing other logics based on self-management and solidarity, contrary to the current business and profit concentration trend. In turn, if these are reflected in a proposal of social transformation, with emergence of new protagonists. The TBC project final evaluation report in East Timor gives empirical elements, focusing on three communities/coopera-

\footnotetext{
1 Este trabalho resulta da comunicação apresentada no "Workshop Sustentabilidade, Terceiro Setor e Redes Sociais em Debate - 1", organizado pelo Centro de Investigação em Sociologia Económica e das Organizações (Socius) e o Research in Social Sciences and Management (CSG), em 2 de fevereiro de 2016, no Instituto Superior de Economia e Gestão (Iseg) da Universidade de Lisboa.

2 Doutora em Sociologia Econômica e das Organizações pelo Instituto Superior de Economia e Gestão da Universidade de Lisboa (ISEG). Pós-doutora no Instituto de Geociências da Universidade Federal Fluminense (UFF). Lisboa, Lisboa, Portugal. E-mail: carolinaleao5@gmail.com
} 
Tourism in Analysis

tives. The study shows the existence of new protagonists sharing powers and knowledge, leading to a horizon of social emancipation based on conduct codes and a set of collaborative management procedures.

Keywords: Community-based Tourism; Other Economies; Social Emancipation.

\section{Resumen}

El sentido de comunidad ha sido la idea fundamental del Turismo de Base Comunitaria $(T B C)$, asociando formas comunes de organización y gestión, en la que esta es la principal beneficiaria. En este artículo se busca conocer cuáles mecanismos de colaboración y gestión las comunidades receptoras han desarrollado que señalan otra lógica basada en la autogestión y la solidaridad, frente a la tendencia a la concentración empresarial y al beneficio. A su vez, si éstos reflejan una propuesta de transformación social, con la aparición de nuevos sujetos protagonistas en el proceso. Se obtienen los datos empíricos a partir del corte de la información incluida en el informe de evaluación externa final de un proyecto de $T B C$, en Timor Oriental, con enfoque en tres comunidades/cooperativas. El estudio reveló que nuevos sujetos se organizan en la distribución del poder y de conocimiento compartidos, a través de los códigos de conducta y de un conjunto de procedimientos de gestión colaborativa, que apunta a un horizonte de emancipación social.

Palabras clave: Turismo de Base Comunitaria; Otras economías; Emancipación social.

\section{Introdução: Turismo para quem? Como?}

Durante os últimos sessenta anos o turismo converteu-se num dos setores econômicos com maior potencial de crescimento em nível mundial, de forma praticamente ininterrupta, apesar de abalos ocasionais (OMT, 2015). Para muitos países o turismo receptor significa uma fonte imprescindível de receitas de moeda estrangeira, associada à criação de emprego e oportunidades de desenvolvimento. Entretanto, tais expetativas nem sempre se traduzem em efeitos positivos quando nos interrogamos: a quem esse setor tem realmente beneficiado? Que tipo de impactos se revelam no seu entorno?

Essas indagações nos levam a identificar o domínio das corporações transnacionais no setor, responsável pela expansão de alguns dos modelos de "paraísos exóticos", entre os quais os de origem espanhola que se têm alargado fundamentalmente para América Latina e Caribe. Segundo Buades (2012), a região concentra cerca de 9\% do volume mundial de visitantes, sendo que 45\% têm como destino o México e América Central. Nesse contexto, a Sol Meliá controla cerca de $20 \%$ da oferta hoteleira em Cuba, tendo expandido para aproximadamente 11 países, entre os quais Brasil, México e República Dominicana. 
Tourism in Analysis

Seguem-se outras cadeias, como Barceló, com cerca de 30 hotéis na região; RIU, com 11 no México e 8 na República Dominicana; Iberostar, presente em 29 destinos, assim como a Fiesta Hotels, com 9 empreendimentos na zona. Considerando a potência econômica de cada uma dessas cadeias, Buades (Ibidem) enfatiza a sua capacidade de crescimento e alargamento vertical no setor. Assim, apesar do crescimento macroeconômico dos países de destino, essas receitas têm consagrado aos países mais empobrecidos a condição de fornecedores de mão de obra barata e dos seus recursos naturais, sendo que apenas uma pequena parte destas ficam nos países de destino, tal como ressalta Gascón:

la mayor parte acaba en las arcas de empresas de los países ricos. Por contra, sus impactos en el nivel de vida de la mayoría de la población anfitriona y en su ecosistema suelen ser altamente perjudiciales: crecimiento del Índice de Precios al Consumo por encima de los ingresos; aumento de las diferencias socio-económicas; sobreexplotación y contaminación de recursos naturales; desvío de los usos tradicionales del agua para cubrir las necesidades de infraestructuras turísticas; incremento del precio de la tierra; deterioro de las condiciones laborales; sustitución de sectores productivos tradicionales; etc. (2012a, p. 28).

Esse quadro tem sido muito frequente nas últimas décadas. Para o seu funcionamento a atividade turística necessita recorrer ao património natural, como a água, terra, energia, trabalho, capital público e privado, investimento etc. Gascón (2012b) revela que nos locais onde esse modelo de turismo se instala há uma tendência para a redução das atividades agrícolas, devido ao monopólio da terra, água, as prioridades de investimento público em prol da atividade, os ditames dos planos de desenvolvimento governamentais, o tipo de força de trabalho exigida, entre outros fatores. Assim, tende a favorecer processos especulativos de utilização do solo habitável, excluindo as populações locais ou criando-lhes dificuldades.

Como alternativa, o autor argumenta que se as populações participassem de forma igualitária na gestão do turismo, os problemas aqui levantados seriam minimizados. Entretanto,

Lo que predomina es una escena en el que el control y gestión, y el acceso a los beneficios, de cada sector económico corresponde a sectores de población diferentes; incluso a sectores de población que no son locales. En esta situación, que un sector económico entre en crisis por perder acceso a recursos necesarios para su sostenibilidad comporta que la población que lo gestiona y 
vive de él se empobrezca. Cuando esto sucede, el turismo comporta importantes costos sociales: segmentación étnica, acentuación de la desigualdad social, erosión cultural, empobrecimiento del capital humano, etc. (Ibidem, p. 18)

Sendo assim, a reflexão que aqui estimulo é assente em experiências concretas cuja racionalidade econômica (aqui compreendida num sentido integrado, incorporando as dimensões políticas, sociais, culturais, entre outras) contraria a lógica de concentração destas corporações, através de mecanismos colaborativos de controle e gestão da atividade turística por parte das comunidades recetoras. Nesse sentido, o Turismo de Base Comunitária (TBC) tende a contrapor os pressupostos do lucro corporativo, a opacidade nas formas de gestão e o controle vertical do património natural e cultural, permitindo o protagonismo de novos atores.

Entretanto, num mundo globalizado e dominado pela lógica capitalista, propício para que a atividade turística seja controlada pelos interesses corporativos, que mecanismos diferenciados de gestão e controle da atividade estão a ser desenvolvidos por essas comunidades, configurando uma partilha de poderes e conhecimentos ancorados pela autogestão e solidariedade? Que elementos comportam as experiências de TBC, que permitam concluir que novos atores estão em cena a partir da dinâmica relacional que estes supostamente estimulam? Neste artigo procurou-se refletir sobre tais questões a partir dos elementos encontrados em três experiências realizadas em Timor Leste, nas comunidades situadas em Tutuala, Maubisi e Maubara, de forma a compreender se estes se evidenciam como proposta de transformação social, refletida no aparecimento de novos atores, enquanto sujeitos protagonistas no processo de TBC. Para tal, recorreu-se aos conceitos de outras economias, autogestão e emancipação social como mediadores desta reflexão.

Trata-se de um estudo empírico, cujos elementos de análise são obtidos no trabalho de campo realizado pela pesquisadora por meio da Cooperativa Mó de Vida, culminando na elaboração de um relatório de avaliação final externo, da sua autoria, no âmbito do projeto "Ahimatan Ba Futuro - Redução da pobreza em Timor-Leste através do turismo de base comunitária"3. Este foi uma iniciativa do Centro de Intervenção para o Desenvolvimento Amilcar Cabral Portugal (CIDAC) e da Fundação Haburas (Timor Leste).

\footnotetext{
3 Co-financiado pela Comissão Europeia e pelo Camões - Instituto da Cooperação e da Língua, Portugal, foi objeto desta avaliação final externa tendo como entidade responsável a Mó de Vida Cooperativa de Consumidores, CRL (ONG), a convite do CIDAC, encerrado o período de 54 meses de execução.
} 
O baixo nível de qualificação formal da população e o isolamento proveniente da história recente do país foram algumas das razões encontradas para a ausência de diversificação das atividades socioeconômicas, destacando-se a agricultura de subsistência. Dessa forma, o $\mathrm{TBC}$, tendo como foco a formação das comunidades envolvidas para a elaboração dos seus programas de visitas e a autogestão das infraestruturas criadas, foi visto pelas entidades promotoras como possibilidade de iniciativa complementar à(s) existente(s), de modo a estimular a liderança e autonomia financeira das comunidades/grupos envolvidas(os).

O projeto focalizou três áreas de interação comunitárias: (1) O Sucu de Tutuala - Cooperativa Valu Sere - criada no dia 28 de outubro de 2007 na sequência da adoção de um código de conduta como estatuto da organização. As principais atividades são a gestão de um serviço de restaurante e alojamento (oito quartos), de um quiosque para a venda de produtos básicos e a produção e comercialização de artesanato tradicional; (2) O Suco de Maubisse, aldeia de Lekitehi - Cooperativa Hakmatek - criada em 2007, cujas atividades incluem a produção hortícola e a entreajuda dos membros para a salvaguarda do património ambiental; (3) O Suco de Vatuvou (subdistrito de Maubara), aldeias de Lisalara e Siamanaru - Grupo Comunitário Laloran, formalmente registrado como Cooperativa Laloran, em 29 de maio de 2010.

A coleta das informações empíricas foi realizada entre 23 de julho e 3 de agosto de 2014, em Timor Leste, com atividades desenvolvidas em Dili e nos Distritos de Tutuala, Maubissi e Maubara, envolvendo: (1) 5 membros da Cooperativa Valu Sere, 1 coordenador do coletivo em funções e 1 animador comunitário da Fundação Haburas; (2) 7 membros da Cooperativa Hakmatek, 1 coordenador do coletivo em funções e 1 animadora comunitária da Fundação Haburas; (3) 5 membros da Cooperativa Laloran, 1 coordenador do coletivo em funções; 1 animador comunitário da Fundação Haburas. Em todos os casos, realizou-se sessões em grupos, dinamizadas pela investigadora, assim como entrevistas (conversas) individuais.

Vários atores que interagiram com o Projeto Ahimatan foram entrevistados(as), de forma a obter diferentes perceções sobre esses contextos, entre os quais: 1 professor do Departamento de Desenvolvimento Comunitário da Universidade Nacional de Timor Leste; o Secretário de Estado do Emprego e Formação Profissional na Secretaria de Estado, Política e Formação Profissional (SEPFOP); 2 representantes da PARCIC - PARC Interpeoples' Cooperation (Japão); 1 representante do Ministério do Turismo e 2 graduandos em Desenvolvimento Comunitário, da Faculdade de Ciências Sociais e Políticas da UNTL. 
Tourism in Analysis

De forma a aproximar as informações obtidas aos objetivos deste artigo, foi realizado um recorte daquelas que integram o relatório original, considerando as aprendizagens destas experiências em 2 níveis: (1) quanto à aceitação e apropriação da iniciativa pelos grupos comunitários; (2) os níveis de autonomia alcançados nos aspetos de gestão do grupo, de gestão financeira e de prestação de serviços ao visitante.

\section{Turismo de Base Comunitária (TBC): o que está em causa?}

O TBC tem sido foco da atenção de diversos(as) estudiosos(as) nos últimos anos, apesar da sua caracterização e atividades serem consideradas recentes, com pouco mais de uma década (Branquinho, 2012). A compreensão do conceito é complexa, incorporando diferentes denominações, aproximações e distanciamentos quanto aos seus pressupostos (turismo sustentável, turismo responsável, turismo justo, turismo ético, turismo solidário...). Sem entrar nestas particularidades, como ponto de partida concordo com Irving (2009, p. 111-112) quando refere que

[c]onsiderando que o turismo, em qualquer de suas formas de expressão e intervenção, interfere na dinâmica sócio-ambiental de qualquer destino, o turismo de base comunitária só poderá ser desenvolvido se os protagonistas deste destino forem sujeitos e não objetos do processo. Neste caso, o sentido de comunitário transcende a perspectiva clássica das "comunidades de baixa renda" ou "comunidades tradicionais" para alcançar o sentido de comum, de coletivo. [...] O protagonismo social resulta do sentimento de pertencimento e do poder de influência sobre os processos de decisão, e só pode ser expresso plenamente quando o ator social se reconhece como agente do processo de construção da realidade e da dinâmica de desenvolvimento.

Outro aspeto é o fato de que o $\mathrm{TBC}$ pode se afirmar como contraponto às formas de turismo de cariz corporativo e massificado, ao permitir "outro modo de visita e hospitalidade" (BURSZTYN; BARTHOLO; DELAMARO, 2009, p. 86), ainda que praticado num mesmo destino, já que este requer menores infraestruturas e serviços, de forma a valorizar o património natural e a cultura local, o que não se coaduna com a perspetiva restrita de percorrer rotas exóticas. Nesse sentido, o que se evidencia é a ideia do respeito pelas 
heranças culturais e tradições locais, podendo servir de veículo para revigorá-las e mesmo resgatá-las. Tem centralidade em sua estruturação o estabelecimento de uma relação dialogal e interativa entre visitantes e visitados. Nesse modo relacional, nem os anfitriões são submissos aos turistas, nem os turistas fazem dos hospedeiros meros objetos de instrumentalização consumista. (Ibidem, p. 86)

Essa argumentação vai de encontro ao estudo de Branquinho (2012), ao assinalar que diversas organizações europeias envolvidas com o TBC organizam encontros preparatórios com os visitantes, de modo a aprofundar as informações sobre as comunidades recetoras, bem como os objetivos das viagens, de maneira a consciencializá-los(as) para as vivências diferenciadas dessa proposta. A sua pesquisa revela, ainda, que os principais benefícios do TBC percecionados pelas organizações europeias envolvidas nessa atividade são:

i. Interação da população com os turistas; ii. O papel da mulher com o consequente incremento da sua autoestima; iii. A recuperação e valorização de saberes e práticas ancestrais; iv. A diversificação produtiva, a criação de emprego e a criação de recursos económicos; v. Os melhoramentos de infraestruturas e a dinamização da economia local. (Ibidem, p. 103)

As propostas do TBC, como contraponto aos modelos corporativos do tudo incluído/all inclusive, desenraizados dos espaços comunitários e das relações com as populações, parece ter potencial para estimular as relações horizontais, pela via da participação das comunidades, o que impele ao surgimento de novos sujeitos políticos, como protagonistas dos seus processos de decisão, controle e gestão do seu patrimônio natural, cultural, econômico e social. Entretanto, tal como alertam Bursztyn, Bartholo e Delamaro (2009) não se trata desses processos serem imunes às influências externas, conflitos internos e de interesses. Na perspetiva dos autores

[o] que se destaca é o significado de tais empreendimentos comunitários para a democracia e a qualidade de vida, quer as comunidades estejam ou não reunidas em cooperativas, micro-empresas, sindicatos ou outras formas de livre associação; e quer existam ou não redes solidárias com organizações não-governamentais internacionais ou apenas nacionais. As parcerias - acordos e pactos negociados para a implementação de tais projetos tanto junto à administração pública local como a outros níveis de governo e ao setor privado são elementos constitutivos da democracia participativa e do desenvolvimento situado e sustentável. (p. 88) 
Apesar de concordar em parte com o argumento desses estudiosos, é preciso ter em conta se as formas de organização e as escolhas das parcerias estimulam ou não a horizontalidade nas relações, a partilha de poderes e saberes, a transparência e a confiança, entre outros aspetos associados às formas de cooperação e solidariedades "desejadas", que permitam o amadurecimento dessas experiências e não comprometam a sua longevidade.

Um estudo realizado por Maldonado (2009), no Equador, identifica diferentes formas de associação comunitárias no TBC, o que é interessante, embora recorra sistematicamente ao termo "negócio" para argumentar sobre o tema, o que parece redutor diante das dimensões que as diferentes propostas articulam (econômica, mas também política, social, cultural, entre outras). De qualquer forma, o teor da sua sistematização ilustra positivamente o que pretendemos focalizar:

a. Pela autogestão do negócio turístico - implica na participação de seus membros em todas as etapas operacionais da atividade, sem excluir a colaboração com atores externos, nomeadamente $\mathrm{ONG}$, universidades, governo, entre outros;

b. Parceria de negócios com uma empresa privada - por meio da contratualização entre a comunidade e um investidor. Os sócios contribuem com os territórios comunais, conhecimentos coletivos, dinheiro, competências técnicas e empresariais, por exemplo. A comunidade comparticipa nos lucros variáveis, recebe uma renda fixa, pode ter cargos administrativos e, entre 10 e 15 anos, torna-se proprietária do investimento, mantendo ou não a parceria;

c. Parceria comercial com operadoras de turismo: um acordo é realizado entre uma operadora ou agência de viagens com a comunidade, para acolher os turistas. Esta fixa o valor a ser pago diretamente pelo turista ou recebe comissão da organização emissora. A operadora é responsável pela promoção e comercialização do produto, bem como o fluxo de turistas. Outras formas de apoio podem existir por parte da organização emissora, tais como: formação, assessorias diversas, empréstimos, entre outros;

d. Concessão de recursos comunitários em usufruto: uma operadora privada solicita à comunidade a utilização temporária dos recursos naturais de seu território e serviços culturais. Como forma de compensação, a empresa assume algumas obrigações junto da comunidade, como a prestação de trabalho temporário, investimento ou outra modalidade (o que nem sempre é cumprido);

e. Trabalho assalariado para operários: trata-se da "proletarização de famílias indígenas" (Ibidem, p. 36), já que não existe um projeto comunitário. Uma empresa privada realiza atividades turísticas no entorno do espaço comunitário e algumas famílias participam individualmente na operação turística através da prestação de serviços, cuja mão-deobra é assalariada e temporária; 
f. Formas híbridas: em que algumas comunidades recorrem a parcerias com operadoras privadas para receberem turistas em troca de trabalho assalariado. A comunidade investe nas infraestruturas (estadia, transporte fluvial, guias nativos) e aproveita as oportunidades de emprego proporcionadas pela empresa, distribuindo os rendimentos entre os membros, através de um sistema rotativo.

Tais exemplos indicam formas de organização interna e de parcerias que modificam a construção relacional das pessoas, dando corpo às diferentes expressões do $\mathrm{TBC}$, com maior ou menor protagonismo e controle comunitário dos processos. Ao considerar que qualquer experiência de TBC tende a coexistir com práticas e pensamentos hegemônicos do mundo globalizado, assentes em relações de poder-saber verticais e certos indicadores de sucesso, enfatiza-se a preocupação inicial de conhecer que mecanismos colaborativos de gestão estão presentes em algumas dessas experiências, sinalizando para a transformação social, pela via da autogestão e a solidariedade, e gerando novos sujeitos protagonistas nesse processo.

\section{TBC: outras economias estão em curso? Que possibilidades de emancipação social?}

A globalização contemporânea, neoliberal, alicerçada pelas novas tecnologias, são cada vez mais promotoras de invisibilidades, sendo atravessadas por discursos e formas relacionais de convivência e organização assentes maioritariamente na racionalidade capitalista, em que a opacidade de um ser designado por "mercado", naturaliza a dominação por força de uma figura "diluída, vaga, engendrando a ficção imprecisa da 'individualidade soberana'.” (CATTANI, 2009, p. 177). O trabalho tem sido um dos eixos centrais no fortalecimento dessa lógica de reprodução social, seja pela via da inserção precária e pontual no mercado, desqualificando-o sistematicamente e atirando-o para um limbo de incertezas, seja pela subordinação direta do trabalho dependente e assalariado. Nesse sentido, a ideologia capitalista tem-se mostrado eficiente, em especial em termos cognitivos - capitalismo cognitivo - (LAZZARATO, 2006), já que não somente os meios de produção tendem a ser dominados, mas a produção de desejos e vontades que encantam para o consumismo e estimulam o mimetismo de comportamentos e discursos, que comprometem a emancipação social.

Logo, o campo das "outras economias" revela-se um espaço aberto ao estudo de práticas socioeconômicas assentes em outras racionalidades e formas de organização da vida material 
(SANTOS, 2015), que abala a formulação da economia com foco na empresa capitalista, no trabalho subordinado-assalariado e no mercado (do tipo capitalista), afirmando o que GibsonGraham (2007) diz ser uma parte reduzida das atividades por meio das quais temos vindo a produzir, trocar e distribuir valores. No seu entender, esta perspetiva permite ampliar as conceções de economia, situando-a como "um corpo abrangente e científico do conhecimento sob suspeita crítica, por seu foco estreito e efeitos mistificadores" (p. 3, tradução minha). Assim sendo, a multiplicidade de experiências de solidariedade e cooperação, levadas a cabo a partir de outras lógicas de exercício do trabalho, tendem a ser produzidas como ausências e desacreditadas, lembrando Santos (2003), diante da ideologia ${ }^{4}$ dominante. O que está em causa é a disputa epistemológica de outros sentidos, de modo a contribuir para a criação, recriação e revitalização das suas dinâmicas, de forma a resgatá-las da invisibilidade. Em meio a essa tensão, reforçamos a afirmação de Santos e Rodríguez, de que a contribuição das culturas marginalizadas pela hegemonia capitalista é fundamental, na medida em que

As formas alternativas de conhecimento são fontes alternativas de produção Na procura de alternativas à produção capitalista, o contributo de culturas minoritárias ou híbridas, marginalizadas pela hegemonia do capitalismo, e o da ciência moderna é fundamental. [...] Existem formas de encarar/ver o mundo que estabelecem uma relação radicalmente diferente da capitalista/moderna entre seres humanos e natureza, entre produção e consumo, entre trabalho e tempo livre, entre o uso e o lucro e entre desenvolvimento e crescimento. $\mathrm{O}$ que é preciso, então, não é apenas respeitar a diversidade cultural que permite a sobrevivência destas visões de mundo, mas também aprender a partir delas para construir um paradigma de conhecimento e acção cosmopolita distinto do que está subjacente à globalização neoliberal. (2003, p. 60-61)

Portanto, o esforço de resgatar da invisibilidade outras racionalidades (outras economias), situadas no calabouço das experiências de TBC aqui estudadas, tem como propósito procurar nas suas entranhas a centralidade do trabalho, na contra corrente da acumulação do capital, os laços de solidariedade construídos e a combinação de diferentes modalidades de associação, para além da desmercantilização da relação com a natureza.

\footnotetext{
4 Compreendo o conceito de ideologia à luz da perceção de Mészáros (2010, p. 65) como “[...] forma especifica de consciência social, materialmente ancorada e sustentada."
} 
Ao ressignificar o trabalho, como ato de criação e princípio educativo-pedagógico de superação do discurso e da representação dominantes, abre-se um campo de possibilidades para olhar o horizonte de emancipação social, na medida em que os sujeitos individuais e/ou coletivos confrontam a racionalidade dominante da economia, com novas formas de exercício do poder-saber pela autonomia, a autogestão ${ }^{5}$ a solidariedade. Ao resgatar tais experiências da invisibilidade e do descrédito, confronta-se a colonialidade do $\operatorname{poder}^{6}$ e do saber ${ }^{7}$, como uma das heranças do paradigma moderno-eurocêntrico, que tem inferiorizado os novos conhecimentos produzidos pelos sujeitos políticos emergentes destes processos, ao emancipar-se de tais padrões cognitivos. Entretanto, perspetivar a emancipação social significa vasculhar um conjunto de princípios, conceitos e processos materiais sobre os quais outras expressões aparecem para dar-lhe sentido - autoemancipação proletária, autogoverno, socialismo, sociedade autogerida e sociedade dos produtores livremente associados (CATTANI, 2009). Segundo o autor, o conceito de emancipação social está relacionado com “o processo ideológico e histórico de liberação por parte de comunidades políticas ou de grupos sociais da dependência, tutela e dominação nas esferas econômicas, sociais e culturais" (Ibidem, p. 175). Por isso, "emancipar-se significa livrar-se do poder exercido por outros, conquistando, ao mesmo tempo, a plena capacidade civil e cidadã no estado democrático de direito" (Ibidem, p. 175). Dessa forma, emancipação social está relacionada com a autonomia, ou seja,

\footnotetext{
5 Considerando a complexidade que envolve a compreensão da autogestão, realizamos uma aproximação do termo a autores como Mészáros (2009), que sustenta que a autogestão não pode ser analisada no sentido restrito da dimensão microeconómica, como a que se desenvolve no interior de algumas fábricas, já que esta também se vincula ao contexto de luta por transformações na sociedade, num sentido abrangente. Tiriba (2008, p. 83), por sua vez, acrescenta que "[no] sentido político, econômico e filosófico, autogestão é um conceito que encerra a ideia de uma forma de organização social em que os sujeitos têm autonomia e autodeterminação na gestão do trabalho e em todas as instâncias das relações sociais. E realça que o seu projeto abarca a "propriedade comum e a posse dos meios de produção da vida social e, por conseguinte, o controle coletivo e soberano das relações que os grupos sociais estabelecem com a natureza e entre si no processo de produção da existência humana".

6 Segundo Quijano (2009), a colonialidade está na intersubjetividade do mundo e, apesar de presente no colonialismo, tem apresentado uma longevidade e enraizamento ainda maior nos últimos quinhentos anos. $\mathrm{O}$ colonialismo, no entanto, está relacionado a uma estrutura de dominação e exploração "onde o controle da autoridade politica, dos recursos de produção e do trabalho de uma população determinada domina outra de diferente identidade e cujas sedes centrais estão, além disso, localizadas noutra jurisdição territorial” (p. 73).

7 Para Mignolo (2003, p. 632), a cumplicidade entre a modernidade e o conhecimento (cientifico) tem como resultado a colonialidade do saber "como negação epistêmica planetária". Assim, defende que, atualmente, "a descolonização já não é um projeto de libertação das colônias, com vista à formação de Estados-nação independentes, mas sim, o processo de descolonização epistêmica e de socialização do conhecimento" (Ibidem).
} 
Tourism in Analysis

uma comunidade política é emancipada, é livre, quando suas leis não são impostas por processos repressivos, tutelares ou paternalísticos; é autônoma quando não obedece a regramentos subjetivos, adventícios ou arbitrários; é, verdadeiramente, emancipada, quando a lei maior é o bem comum, objetivo e universalizador. Na sociedade emancipada, os indivíduos possuem o máximo de liberdade, mas esta é pautada pela igualdade, pela reciprocidade de direitos e obrigações, enfim, pelo processo civilizador que garante a livre expressão respeitosa da diferença e da liberdade do outro. (Ibidem, p. 175)

Numa análise acerca da potência emancipadora da autonomia dos sujeitos, Rey (2011, p. 169 , grifos da autora) considera o significado de autonomia ${ }^{8}$ quando se trata da organização e gestão dos assuntos comuns a partir dos seguintes elementos:

1. Quién es el "sujeto" real o potencialmente autónomo: $i * e l$ individuo, *la clase, *el grupo social, *la organización, *la multitud, *la comunidad, *el pueblo, *las masas, *la sociedad?. ¿Cómo se practica y extiende la autonomía? ¿Cómo se define y conforma su subjetividad? ¿Qué se entiende por subjetividad y subjetivación?

2. Cuál es el alcance de la autonomía, en qué "escala" se concibe su ejercicio: ¿la asociación voluntaria para un fin específico, la fábrica, la escuela, el barrio, la comunidad territorial, el municipio, la agrupación política, la nación, el planeta? En su caso ¿cómo se replicarían las prácticas autonómicas en colectivos sociales múltiples y complejos?

3. Cómo se expresa la autonomía, es decir, cuáles son las reglas de juego para la participación individual y colectiva en la toma de decisiones: ¿horizontalidad, asamblea, delegación, representación?

4. Cuál es la forma democrática de existencia de un colectivo autónomo. El ideal perfecto de democracia directa, en el que todos participan, plenos de voluntad y conciencia, de las decisiones sobre asuntos colectivos - la historia lo enseña -, parecería sólo practicable en comunidades muy pequeñas y sencillas, cuya agenda de cuestiones comunes tiene un formato limitado. También podría ser viable en ámbitos acotados, como un lugar de trabajo, una escuela, una organización social, una comunidad territorial, etcétera. Sin embargo, también aquí se ponen en juego otras cuestiones que merecen una reflexión particular.

\footnotetext{
8 A autora associa autonomia à conceção de Held (1992, p. 325), em que esta “connota la capacidad de los seres humanos de razonar conscientemente, de ser reflexivos y autodeterminantes. Implica cierta habilidad para deliberar, juzgar, escoger y actuar entre los distintos cursos de acción, posibles en la vida privada al igual que en la pública".
} 
Tourism in Analysis

a) ¿Qué características y tamaño debe tener el espacio asambleario donde todos puedan realmente emitir su opinión razonada y escuchar y evaluar los argumentos de los demás, para alcanzar la mejor decisión posible? ¿Es necesario que estén y participen todos para que una decisión sea legítima? ¿Basta con que estén notificados? ¿Quién está habilitado, entonces, para definir el momento y el lugar? ¿El que no va, delega la representación o preserva su capacidad de decisión? ¿Hay un deber de participar en las decisiones y acciones colectivas o es un derecho que se ejerce o no? ¿Las personas deben influir en las decisiones en proporción a cómo son afectadas por ellas? ¿Qué es lo que legitima una decisión tomada en un ámbito asambleario: el espacio mismo definido como abierto o el número de participantes, o una combinación de los dos? ¿Y quién y cómo decide esto?

b) ¿Qué recursos intelectuales y de información deben poseer los miembros de ese colectivo que toma decisiones para estar en igualdad real de condiciones, a la hora de decidir? Si la opinión de todos sobre todo es equivalente, ¿existe el derecho a argumentar una propuesta en función de saberes específicos sobre la cuestión en juego? Quienes están directamente afectados por una cuestión, ¿deberían o no tener mayor incidencia en la decisión final?

Pode-se então concluir que construir experiências de TBC num horizonte da emancipação social não é tarefa singela. A seguir, partilhamos as aprendizagens dos processos estudados.

\section{Valu Sere, Hakmatek e Laloran: o que ensinam sobre a emancipação social?}

Começo por salientar que os níveis de autonomia alcançados pelos grupos comunitários é fruto de um processo pedagógico desenvolvido ao longo das formações realizadas, aquando da implementação do projeto de TBC. Durante a avaliação externa foi feito um levantamento temático dos conteúdos formativos e das metodologias utilizadas para, em seguida, relacionar aos depoimentos obtidos in loco, numa tentativa de cruzamento das informações.

Houve uma preocupação de combinar os conteúdos técnicos aos valores atribuídos ao TBC, em especial nos blocos temáticos "Gestão e organização cooperativista" e "Gestão corrente de atividades de hotelaria e restauração", assim como nas visitas de estudo. Assim, realçamos alguns dos conteúdos pedagógicos trabalhados no processo de aprendizagem vivencial: (1) Da ética: com o estímulo à construção dos princípios e valores de cada grupo, posteriormente assentes nos "Códigos de Conduta" consensualizados; (2) Técnico: no âmbito da hospitalidade, restauração, gestão financeira, gestão do alojamento, segurança, entre outros aspetos. 
Recorrendo às metodologias participativas, de caráter vivencial, os(as) participantes são estimulados(as) a comparar criticamente a proposta do TBC com as de cariz essencialmente empresarial. O debate sobre as diversas tipologias de turismo, desde o "turismo de massa" àqueles com afinidades com o TBC (como o ecoturismo) foram medidas importantes para o aprofundamento do conceito e o desenvolvimento de uma visão analítica sobre o trabalho, as relações entre os membros e as formas de interação com o meio envolvente.

Durante as entrevistas realizadas com os membros das três cooperativas, procurou-se identificar como cada experiência integrou as aprendizagens do processo formativo às suas práticas cotidianas. Para tal, partimos dos seguintes referenciais: (1) o funcionamento dos grupos de trabalho; (2) gestão financeira; (3) complementaridades com as atividades tradicionais e com a comunidade envolvente.

\section{a. O funcionamento dos grupos de trabalho}

Neste ponto, destaca-se a existência, nas três cooperativas, de códigos de conduta orientadores da relação entre os membros, criados a partir do diálogo e participação desses membros durante o Projeto Ahimatan. Outro aspeto é a rotatividade dos subgrupos de trabalho, para responder às atividades necessárias ao funcionamento dos alojamentos destinados à receção dos visitantes, autogeridos pelos participantes. Nos três contextos os membros não abandonaram as suas atividades tradicionais (a agricultura, por vezes combinada com a criação de animais e, em alguns casos, a pesca artesanal), que coexistem com a atividade do TBC.

$\mathrm{Na}$ Cooperativa Valu Sere, a escala rotativa é de uma semana para cada um dos quatro subgrupos que garantem a gestão do alojamento. Estes se responsabilizam pelos serviços de atendimento dos visitantes no restaurante, nos quartos e no quiosque, onde vendem alguns produtos como água e artesanato. Cada um controla o que acontece durante o período. Essas notas são registradas num livro a que todos(as) têm acesso. Entre as informações constam: (1) atividades realizadas no quiosque - o que foi vendido e respetivos preços; (2) sobre o período de alojamento - número de dormidas; (3) restaurante - número de refeições servidas. Na passagem da gestão semanal, a cada domingo, o subgrupo responsável transmite ao seguinte as informações sobre o movimento realizado, que inclui uma previsão de custos, despesas e receitas. Cerca de doze pessoas integram cada um dos subgrupos com a seguinte divisão das tarefas e número de pessoas: finanças, 1; limpeza dos banheiros, 2; quartos, 2; 
cozinha, 4 ou 5; restaurante, 2 ou 3. Uma reunião entre os membros é realizada antes de passar a gestão ao próximo subgrupo, procurando organizar o trabalho e garantir o fluxo de informações. A cada trimestre há uma reunião geral, com o(a) coordenador(a) geral do grupo. O código de conduta serve de orientação ao funcionamento do grupo quanto: (1) à tentativa de mediação de conflitos, que acontece por consulta ao coordenador de cada subgrupo e, não havendo solução, recorrem ao coordenador geral e, em último caso, apelam ao conselheiro; (2) às questões de propriedade, pois a cooperativa é coletiva, mas a terra é de uma família, que cedeu o espaço para a construção das estruturas; (3) aos serviços de limpeza dos quartos, cozinha e das áreas comuns, que são realizados todos os dias, pelas equipes responsáveis.

Cerca de quarenta pessoas integram a Cooperativa Hakmatek, das cem famílias residentes. Dois subgrupos asseguram a gestão do alojamento. O código de conduta inclui critérios sobre responsabilidades e colaboração no trabalho, entre os quais destacamos: (1) 1 coordenador é responsável pela organização com o grupo; (2) 1 tesoureiro controla o dinheiro; (3) 2 pessoas trabalham na cozinha e 1 na limpeza; (4) existe a rotação semanal de dois subgrupos, sempre às segundas-feiras; (5) a cada três anos o coordenador é substituído; (6) cada subgrupo é composto por dez pessoas e realizam um encontro mensal para a prestação geral de contas; (7) as decisões coletivas são tomadas a cada três meses.

Há um cartaz afixado no restaurante, explicitando o funcionamento do coletivo. É função do coordenador articular o grupo e dar a conhecer as reclamações sobre membros que não cumprem as suas responsabilidades. Se impossibilitado, o vice-coordenador assume este papel. O "tesoureiro" trata do orçamento. O "movi mercadoria” promove o produto local. O(a) “interna” é responsável pela gestão do alojamento. "Relação social” tem a função de mediar conflitos ou as questões que surgem na comunidade, sob consulta ao coordenador.

Dos 60 trabalhadores iniciais, atualmente trabalham 45. O problema mais comum é a distribuição do dinheiro, já que os 15 membros que já não atuam exigem recebê-lo. Entretanto, têm conseguido superar esses problemas com o diálogo, argumentando que "têm o nome no grupo, mas têm que trabalhar." (membro, 2014).

Já a Cooperativa Laloran, que possui igualmente um código de conduta, ressalta os seguintes aspetos do seu funcionamento: (1) disciplina; (2) há que respeitar o outro; (3) regulação da atividade dentro do grupo; (4) existe uma lista de presenças que dá conta da participação dos membros nos encontros; (5) a exclusão de um membro é feita através de: chamada oral; 
chamada por escrito e, por fim, se dá a exclusão do membro; (6) há que reforçar e proteger o ambiente; (7) tomada de decisões partilhada: é preciso ouvir os membros no fórum; (8) trabalham em conjunto, esforçando-se para que tudo corra bem; (9) dois grupos de quinze pessoas (trinta no total) revezam-se na gestão do alojamento.

Quanto à organização há: 1 coordenador geral e 1 vice-coordenador por subgrupo; 1 tesoureiro; 1 guia; 2 promotores/parte comercial; 2 responsáveis pelos quartos; 3 pela cozinha; 1 serve a mesa e 2 seguranças. A limpeza geral é feita por todos(as), diariamente. O revezamento dos subgrupos é feito a cada duas semanas, às segundas-feiras. O grupo enfatiza que construíram juntos o alojamento, com base no atual revezamento na gestão. Foram os próprios membros a conceber o desenho, identificar os materiais adequados e adquiri-los na montanha. Se há disponibilidade, existe entreajuda nas diferentes tarefas. Para além do serviço de alojamento, a cooperativa possui um restaurante para festas e outros encontros, como forma de rentabilizar o espaço. Antes do revezamento quinzenal, há uma reunião para acertar questões sobre as entradas e saídas de dinheiro e planejar a semana seguinte. Mensalmente, há um encontro geral para acordar o que faz falta no grupo, prever e fazer as compras.

Outros aspetos relevantes da gestão coletiva são: (1) a segurança, pois há uma vigilância quanto ao estacionamento, controle das pessoas e animais que entram e dos pertences dos visitantes quando vão ao mar; (2) o sistema de compras, com planificação quinzenal face à chegada dos(as) visitantes, o que inclui os produtos locais para as refeições e materiais de manutenção; e (3) os serviços de limpeza divididos entre homens (limpam os banheiros) e mulheres (os quartos), com colaboração mútua se houver muitos visitantes.

\section{b. Gestão financeira}

Neste item, o foco é a divisão dos benefícios econômicos resultantes da atividade do TBC, associada aos mecanismos de transparência criados para a prestação de contas das organizações. As três cooperativas encontraram formas próprias de distribuir os benefícios gerados, apesar de haver problemas na Cooperativa Hakmatek.

$\mathrm{Na}$ Cooperativa Valu Sere, a divisão dos benefícios é feita com base nos relatórios semanais, sendo que a partilha é realizada a cada três meses: $25 \%$ para a reserva geral; $15 \%$ construção; $10 \%$ manutenção; $75 \%$ divididos como remuneração para as pessoas que trabalham. Os 
conselheiros e idosas(os) recebem 25\%, a cada três meses. Entre os trabalhadores(as), 42 têm rendimentos provenientes do alojamento, com valores igualmente distribuídos para todos(as). Há um controle de entradas e saídas dos(as) visitantes, por meio de um livro de registro que é preenchido e assinado à chegada. É uma das ferramentas de base para o controle da permanência dos visitantes, que inclui o número de diárias, check in/check out, nome do(a) visitante. De julho de 2008 até à data em que foi realizada a avaliação externa, 895 pessoas visitaram Valu Sere, tendo arrecadado aproximadamente 111.002,15 USD de receitas. De 2005 a 2008 não realizaram registros. Em 2005 receberam alguns visitantes e, em 2006, houve um conflito político partidário que desestabilizou o país e instalou uma crise.

No caso da Cooperativa Hakmatek, a divisão dos benefícios tem como base as receitas e despesas geradas com a ocupação do alojamento e o serviço de restaurante, da seguinte forma: (1) apuramento das despesas relacionadas com a manutenção do alojamento; (2) os membros não recebem rendimentos, mas fazem retiradas conforme necessitam. A autorização é dada pelo coordenador e paga pelos responsáveis pelas finanças. O coordenador faz constar no relatório que é apresentado na reunião trimestral.

O controle de entradas e saídas dos visitantes deveria ser registrado num livro existente para o efeito, bem como os montantes recebidos com os serviços prestados. Existem dois livros, onde deveriam registrar: (1) o número de visitantes e as despesas com cada um; quem realizou as compras para o atendimento e lançamento da nota de despesa; (2) o levantamento de dinheiro dos membros e a contribuição para a comunidade. Os empréstimos aos membros são feitos até o valor máximo de 20,00 USD. Nesse livro está supostamente indicado o montante emprestado, a devolução do empréstimo, entre outras despesas.

Entretanto, o primeiro livro tem registros de visitantes e despesas somente até abril (estávamos em julho). O número de visitantes que o preencheram era inferior ao que diziam ter dado entrada. Cerca de cem visitantes, pelo menos, não estavam registrados. Ao indagar sobre esse desencontro, uma das responsáveis revela que os membros se esquecem de apresentar o livro. O primeiro visitante deu entrada em 16 de agosto de 2012 e, até à data do estudo, dizem ter recebido cerca de duzentos. Há um fundo de reserva criado para as despesas de manutenção do alojamento, no valor de 1.000,00 USD, que está sob a responsabilidade de um dos membros. A Cooperativa Laloran definiu que, se as receitas são pequenas, não há distribuição de rendimentos entre os membros, sendo orientadas para as rubricas "fundo de reserva" e 
"manutenção". Para que haja distribuição dos benefícios, as rubricas criadas devem atender aos seguintes montantes: para uma receita de 1.000,00 USD consideram o fundo de reserva de 400,00 USD (40\%); manutenção, 100,00 USD (10\%); distribuição entre os membros, 500,00 USD (50\%). Se o valor previsto para os serviços for considerado grande, todo o grupo decide o que será cobrado e o seu destino. Tais acordos são acautelados de forma transparente.

A organização possui um livro de registro que é preenchido e assinado pelos visitantes à chegada, que inclui o número de diárias, check in/check out, nome do/a visitante, contacto etc. $\mathrm{O}$ controle de entrada é feito por qualquer um(a) dos membros e nunca fica esquecido. No livro é registrado o número de visitantes, nome, data de entrada e saída, nacionalidade, comentários e assinatura. Desde 22 de dezembro de 2011 há um livro oficial de registro. Até à data da avaliação externa foram registrados 249 visitantes, a que acrescem alguns que constam numa lista suplementar, anterior ao livro, o que perfaz cerca de 260.

Há um livro de gestão financeira, semelhante ao de Maubissi, onde constam as receitas e despesas e, igualmente, se há algum tipo de gorjetas. É de destacar que quem dá apoio mais direto ao visitante recebe a gorjeta. $\mathrm{O}$ balanço das receitas e despesas é apurado à saída de cada visitante e por pax, obtendo um valor final. Este é feito pelos membros que estão responsáveis pela gestão da quinzena, quando reúnem e fecham o balanço. Quando outro grupo assume, pode sempre verificar o balanço da quinzena anterior.

\section{c. Complementaridades com as atividades tradicionais e com a comunidade envolvente}

Estas complementaridades se dão, em especial, na interação com as atividades tradicionais, no campo da alimentação, e na valorização da cultura local, com o envolvimento mais alargado das comunidades no TBC, para além dos que participam diretamente nas cooperativas. Segundo o coordenador da Cooperativa Valu Sere houve alterações nas atividades tradicionais da comunidade, com a criação do TBC, em especial com relação às pescas. Antes, esta era realizada sem equipamentos e, agora, é com o auxílio de máquinas e barco. A Cooperativa e outros comerciantes compram o peixe que só a família consumia. Há também um congelador para acondicioná-lo, cuja compra o Estado apoiou.

Os(as) que trabalham em Valu Sere têm outras atividades nas suas hortas, na pesca, na agricultura e com a criação de animais. Entre os pescadores, 3 são membros. Os produtos locais 
são utilizados nas refeições do restaurante e receitas especiais são confecionadas para o efeito. Algumas pessoas processam os produtos para vender em frente às suas casas e as crianças ajudam nessa tarefa, antes de irem para a escola. Normalmente, utilizam a banana, mandioca, abóbora, batata, batata doce, coco e papaia, entre os cultivos locais. As mulheres fazem pudim de abóbora, banana, papaia e elaboram o pisang goreng, com banana, mandioca e milho fritos. O trigo é comprado fora, mas processam a farinha de milho e de mandioca. Como essa tarefa leva algum tempo, preferem o trigo. Se conseguem vender tudo têm como rendimento de cerca de 5 USD brutos, a que têm que descontar o custo do material (farinha, óleo, açúcar, fermento e a madeira). Alguns desses produtos são vendidos em outras quatro comunidades. Quanto aos animais, em Tutuala há muito frango de Timor, que é pequeno e custa cerca de 1,00 USD. Mas há o problema anual da gripe das aves e com a vacinação em geral. O peixe é comprado ao grupo da pesca. Os demais, por vezes, são adquiridos em outras comunidades. O porco é caro, já que custa entre 40,00 ou 50,00 USD, se for pequeno. Da produção dos membros da cooperativa utilizam o milho, a batata, mandioca, talas, banana, papaia, abóbora, folha e flores da papaia, folhas da mandioca e da abóbora e alface (quando existe água). Salientam que os três grupos - Laloran, Hakmatek e Valu Sere - trocaram experiências sobre culinária. Os estudos comparativos foram importantes para conhecer como plantam e que uns podem dar produtos aos outros, além de divulgar aos visitantes que há outros grupos como o de Valu Sere, em Maubara e Maubissi. Não dá para trocar sementes porque o clima e a terra são diferentes. Podem, se possível, comprar e vender produtos entre todos.

$\mathrm{Na}$ Cooperativa Hakmatek, no que se refere aos produtos provenientes dos cultivos locais, se há excedentes na produção, o alojamento compra dos próprios membros do grupo. Os legumes e verduras são sempre da produção local. Se há frango de Timor, compram da comunidade. Se não há, o utilizado é de importação. O peixe é comprado em Aileu, no Sucu de Daisoli, mas os vendedores também se deslocam a Maubissi para vender, já que duas vezes por semana existe um bazar. Neste, são vendidos produtos como legumes, porco, búfalo, vaca e cavalo, provenientes de várias comunidades, sendo que antes do TBC o produto local não era comprado. Dessa maneira, o TBC é fator de valorização dos produtos e da cultura local, até porque já recebem visitantes desejosos(as) de conhecê-la, o que antes não acontecia. Os(as) "avôs(ós)" são envolvidos(as) no trabalho do TBC, já que vivem nas casas tradicionais e contam histórias aos visitantes. Há sete casas tradicionais sendo que, em quatro delas, 
Tourism in Analysis

oito pessoas podem lá ficar. Dizem que "quando as pessoas [visitantes] chegam não acontece nada de mal, porque todas têm informações.” (membro Hakmatek, 2014). De forma geral, reconhecem que a comunidade está contente com a implementação do TBC, em virtude dos visitantes que chegam para conhecer o local, o que favorece a compra de produtos, principalmente os alimentares, como batatas, ovos etc.

Por fim, na Cooperativa Laloran os membros são agricultores, havendo dois pescadores e uma tecelã. Estes criam animais e moram próximos ao alojamento, sendo possível compatibilizar as atividades tradicionais com o TBC e rentabilizá-las por meio da aquisição de produtos aos membros da cooperativa. Exemplo disso é que nas refeições utilizam produtos locais como milho, mandioca, peixe, búfalo, porco e cabrito adquiridos aos membros.

Referem que o frango de Timor é caro em relação ao de importação. Contudo, é o que os visitantes gostam e eles(as) dão preferência (não gostam dos importados). É comprado aos próprios membros, apesar de que, dependendo dos visitantes, utilizam o importado, se não há um pedido formal pelo de Timor. Quando há visitantes, os pescadores do grupo vendem o peixe, preferencialmente, para o alojamento.

Para o processamento de alimentos houve formação, mas não há material para o confecionar, pois não há forno, máquinas ou embalagens. Em casa, os membros muitas vezes não conseguem preparar os produtos tal como no restaurante, pois há carências de óleo e outros produtos necessários.

Por último, verificamos que os atores abrangidos neste processo é significativo, ou seja: 48 pessoas, no total, dos 4 subgrupos que garantem a gestão do alojamento e seus agregados, na Cooperativa Valu Sere; 40 pessoas, dos 2 subgrupos que garantem a gestão do alojamento e respetivos agregados, na Cooperativa Hakmatek e 30 pessoas, dos 2 subgrupos que garantem a gestão do alojamento e seus agregados familiares, na Cooperativa Laloran. Quanto aos atores indiretamente envolvidos detetamos 360 famílias no Sucu de Tutuala; 100 famílias no Sucu de Maubissi e 50 famílias do Sucu de Vatuboro, subdistrito de Maubara. 
Tourism in Analysis

\section{Conclusão}

Essas experiências de TBC, estudadas sob a ótica da emancipação social, apresentam contribuições importantes para o campo das outras economias, já que outras racionalidades são aqui expressas, embora talvez não descodificadas pelos seus sujeitos (em nenhum dos casos mencionaram formas de resistência ou de contraponto à racionalidade capitalista). Entretanto, elaboram uma crítica ao turismo corporativo e ao turismo de massa.

Existem evidências de que a forma como se organizam para assegurar a gestão do TBC não se restringe a uma resposta meramente técnica, para o exercício das suas funções. Sendo o TBC uma atividade complementar, é necessário que os participantes se organizem de forma colaborativa, em que a rotatividade lhes permita a manutenção das suas atividades tradicionais, para além da sua realimentação em função dos produtos que circulam pela via do TBC, havendo uma dinamização colaborativa da pequena economia local.

Há também outros produtos, como o artesanato, que são igualmente contemplados no âmbito do TBC, em que a partilha da cultura local é outro valor reforçado. Acresce a participação dos atores mais idosos, como em Maubissi, como contadores de histórias, com um papel importante na partilha da tradição cultural, oral e o benefício que o TBC também traz para o incremento de atividades relacionadas com a tradição (os avós são atores e se beneficiam diretamente com parte das remunerações do TBC, aplicadas nas iniciativas comunitárias). Outro ponto a realçar são os conteúdos e debates realizados durante as formações que envolveram a ética, entendida como um conjunto de princípios e valores norteadores do TBC (pelo menos de algumas visões sobre o TBC, admitindo que não existe uma única), em que a cooperação, a solidariedade, a transparência e a autonomia podem ser encontradas nos discursos e nas práticas orientadoras dessas experiências, expressas nos códigos de conduta, nas formas diversas de gestão e na relação com as comunidades envolventes.

A preocupação com a transferência da gestão de um subgrupo a outro e as assembleias para a realização de acordos/tomadas de decisões denotam que esses coletivos dão importância à existência de um processo de partilha de poderes. Esta é igualmente revelada na gestão financeira do trabalho, relativamente à divisão dos benefícios oriundos da atividade e dos mecanismos de transparência encontrados para tornar claros os movimentos de receitas e despesas. Para tal, encontraram mecanismos simples, de fácil identificação dos elementos 
Tourism in Analysis

necessários à compreensão de como cada subgrupo pode realizar a sua previsão de despesas, os gastos decorrentes das compras, assim como as receitas e a apuração dos benefícios.

A forma como integram a atividade do TBC às formas de produção e comercialização locais não se restringe a um mero acréscimo de renda à população local. Esta é apenas parte do processo que imprime novos ritmos e dinâmicas de trabalho, assim como novas sociabilidades, uma vez que a forma de gestão compartilhada exige toda uma organização de espaços e tempos para as reuniões sistemáticas, em que se dá conta do apuramento dos benefícios, como serão distribuídos, do debate sobre os problemas emergentes, as formas de intervenção dos diferentes atores e o que é objeto de tomada de decisão coletiva.

Por fim, é possível aprender dessas experiências que novos sujeitos de poder e conhecimentos compartilhados estão presentes nesses espaços, organizando-se a partir do trabalho coletivo, na colaboração com as famílias e respetivas comunidades envolventes. Tais sociabilidades e formas de convivência revelam que, com a autogestão do trabalho, a autonomia destes sujeitos desenha-se no cotidiano dessas relações, retirando-os(as) da condição de objeto executante do trabalho assalariado e subordinado. Nessa condição, o TBC pode ser uma via para que os novos sujeitos construam outras racionalidades - outras economias - através da experimentação de práticas coletivas com um horizonte de emancipação social.

Agradeço ao CIDAC por ter autorizado a utilização das informações do relatório de avaliação externa, em que assenta o presente artigo, e pela divulgação dos nomes das diversas entidades.

\section{Referências}

BRANQUINHO, C. M. Turismo comunitário: enquadramento conceptual, organizacional e impacte. 2012. Dissertação (Mestrado em Gestão e Planejamento em Turismo) - Universidade de Aveiro, Aveiro, 2012.

BUADES, J. Turismo, la globalización invisible. In: BUADES, J.; CAÑADA, E.; GASCÓN, J. (Orgs.). El turismo en el inicio del milenio: una lectura crítica a tres voces. Madrid: Foro de Turismo Responsable; Red de Consumo Solidario; Picu Rabicu y Espacio por un Comercio Justo, 2012. p. 25-27.

BURSZTYN, I.; BARTHOLO, R.; DELAMARO, M. Turismo para quem? Sobre caminhos de desenvolvimento e alternativas para o turismo no Brasil. In: BARTHOLO, R.; SANSOLO, D. G.; 
Tourism in Analysis

BURSZTYN, I. (Orgs.). Turismo de base comunitária: diversidade de olhares e experiências brasileiras. Rio de Janeiro: Letra e Imagem, 2009. p. 76-91.

CATTANI, A. Emancipação Social. In: HESPANHA, P.; CATTANI, A.; LAVILLE, J.-L. (Orgs.). Dicionário internacional da outra economia. Coimbra: Almedina, 2009. p. 175-180.

GASCÓN, J. Empresas transnacionales turísticas de capital español: el neocolonialismo discreto. In: BUADES, J.; CAÑADA, E.; GASCÓN, J. (Orgs.). El turismo en el inicio del milenio: una lectura crítica a tres voces. Madrid: Foro de Turismo Responsable; Red de Consumo Solidario; Picu Rabicu y Espacio por un Comercio Justo, 2012a. p. 28-30.

. Introducción: Apuntes para un análisis crítico del turismo. In: BUADES, J.; CAÑADA, E.; GASCÓN, J. (Org.). El turismo en el inicio del milenio: una lectura crítica a tres voces. Madrid: Foro de Turismo Responsable; Red de Consumo Solidario; Picu Rabicu y Espacio por un Comercio Justo, $2012 b$.

GIBSON-GRAHAN, J. A diverse economy: rethinking economy and economic representation. [s.1.]: [s.n.], 2007. Disponível em: <http://cscs.res.in/dataarchive/textfiles/textfile.2007-11-30.8168238051/ file>. Acesso em: 3 jun. 2016.

IRVING, M. de A. Reinventando a reflexão sobre turismo de base comunitária. Inovar é possível? In: BARTHOLO, R.; SANSOLO, D. G.; BURSZTYN, I. (Orgs.). Turismo de base comunitária: diversidade de olhares e experiências brasileiras. Rio de Janeiro: Letra e Imagem, 2009. p. 108-121.

LAZZARATO, M. As revoluções do capitalismo. Rio de Janeiro: Civilização Brasileira, 2006.

LEÃO, C. V. M. Relatório de avaliação final externa projeto "Ahimatan Ba Futuro - Redução da pobreza em Timor-Leste através do turismo de base comunitária”. Lisboa, 2015.

MALDONADO, C. O turismo rural comunitário na América Latina: gênesis, características e políticas. In: BARTHOLO, R.; SANSOLO, D. G.; BURSZTYN, I. (Orgs.). Turismo de Base Comunitária: diversidade de olhares e experiências brasileiras. Rio de Janeiro: Letra e Imagem, 2009. p. 25-44.

MÉSZÁROS, I. O século XXI: socialismo ou barbárie? São Paulo: Boitempo, 2009.

O poder da ideologia. São Paulo: Boitempo, 2010.

MIGNOLO, W. D. Os esplendores e as misérias da "ciência": colonialidade, geopolítica do conhecimento e pluriversalidade epistémica. In: SANTOS, B. de S. (Org.). Conhecimento prudente para uma vida decente. Porto: Afrontamento, 2003. p. 631-671.

OMT - ORGANIZACIÓN MUNDIAL DEL TURISMO. Panorama OMT del turismo internacional. Jul. 2015. Disponível em: <http://www.e-unwto.org/doi/book/10.18111/9789284416875>. Acesso em: 4 jun. 2016. 
Tourism in Analysis

QUIJANO, A. Colonialidade do poder e classificação social. In: SANTOS, B. de S.; MENESES, M. P. (Orgs.). Epistemologias do sul. Coimbra: Almedina, 2009. p. 73-114.

REY, M. T. La autonomía: entre el mito y la potencia emancipadora. In: ADAMOVSKY, E. et al. (Orgs.). Pensar las autonomías alternativas de emancipación al capital y el Estado. México: Sísifo; Bajo Tierra, 2011. p. 145-207.

SANTOS, B. de S. Para uma sociologia das ausências e uma sociologia das emergências. In:

SANTOS, B. de S. (Org.). Conhecimento prudente para uma vida decente. Porto: Afrontamento, 2003. p. 735-775.

SANTOS, L. L. dos. Consumo, hierarquias sociais e colonialidade econômica: na contramão de uma banalização da consciência. Revista Espaço Ética, São Paulo, v. 2, n. 6, p. 1-20, 2015. Disponível em: $\quad<$ http://revistaespacoetica.com.br/2016/01/26/consumo-hierarquias-sociais-e-colonialidade-economica-na-contramao-de-uma-banalizacao-da-consciencia-por-luciane-lucas-dos-santos/>. Acesso em: 5 jun. 2016.

TIRIBA, L. Cultura do trabalho, autogestão e formação de trabalhadores associados na produção: questões de pesquisa. Perspectiva, v. 26, n. 1, p. 69-94, 2008. Disponível em: $<$ http://www.perspectiva.ufsc.br>. Acesso em: 4 jun. 2016.

Recebido em: 19/06/2016 (1 ${ }^{\mathrm{a}}$ versão) $31 / 10 / 2016$ ( $2^{\mathrm{a}}$ versão)

Aprovado em: 21/11/2016 